\title{
Mesenchymal Stem Cell Secretion of SDF- $1 \alpha$ Modulates Endothelial Function in Dilated Cardiomyopathy
}

\author{
Courtney Premer ${ }^{11}$, Amarylis Wanschel'1, Valeria Porras ${ }^{1}$, Wayne Balkan ${ }^{1,2}$, \\ Tatiana Legendre-Hyldig', Russell G. Saltzman', Chunming Dong ${ }^{1,2}$, \\ Ivonne Hernandez Schulman ${ }^{1,2,3 *}$ and Joshua M. Hare ${ }^{1,2}$
}

'Interdisciplinary Stem Cell Institute, Miller School of Medicine, University of Miami, Miami, FL, United States, ${ }^{2}$ Department of Medicine, Miller School of Medicine, University of Miami, Miami, FL, United States, ${ }^{3}$ Katz Family Division of Nephrology and Hypertension, Miller School of Medicine, University of Miami, Miami, FL, United States

\section{OPEN ACCESS}

Edited by:

David H. Wasserman, Vanderbilt University, United States

Reviewed by: Daniele Vergara,

University of Salento, Italy

Nada A. Abumrad,

Washington University in St. Louis, United States

Dmitri Samovski,

Washington University School of Medicine in St. Louis, United States

*Correspondence: Ivonne Hernandez Schulman ISchulman@med.miami.edu

tThese authors have contributed equally to this work

Specialty section:

This article was submitted to Lipid and Fatty Acid Research,

a section of the journal

Frontiers in Physiology

Received: 06 June 2019 Accepted: 02 September 2019 Published: 24 September 2019

Citation:

Premer C, Wanschel A, Porras V, Balkan W, Legendre-Hyldig T, Saltzman RG, Dong C, Schulman IH and Hare JM (2019) Mesenchymal Stem Cell Secretion of SDF-1a Modulates Endothelial Function in Dilated Cardiomyopathy. Front. Physiol. 10:1182. doi: 10.3389/fphys.2019.01182
Background: Endothelial dysfunction contributes to the pathophysiology of dilated cardiomyopathy (DCM). Allogeneic but not autologous mesenchymal stem cells (MSCs) improve endothelial function in DCM patients. We hypothesized that these effects are modulated by release of stromal derived factor- $1 \alpha$ (SDF-1 $\alpha)$.

Methods: Plasma TNF $\alpha$ and endothelial progenitor cell-colony forming units (EPCCFUs) were assessed at baseline and 3-months post-injection in a subset of POSEIDON-DCM patients that received autologous $(n=11)$ or allogeneic $(n=10)$ MSCs. SDF-1 $\alpha$ secretion by MSCs, endothelial cell (EC) TNF $\alpha$ mRNA expression, and levels of reactive oxygen species (ROS) in response to SDF-1 $\alpha$ were measured in vitro.

Results: As previously shown, DCM patients $(n=21)$ had reduced EPC-CFUs at baseline ( $3 \pm 3$ ), which were restored to normal by allogeneic MSCs 3-months posttreatment $(\Delta 10 \pm 4)$. DCM patients had elevated baseline plasma TNF $\alpha(n=15$, $22 \pm 9.4 \mathrm{pg} / \mathrm{mL})$. Allogeneic MSCs $(n=8)$ decreased, and autologous MSCs $(n=7)$ increased, plasma TNF $\alpha(-7.1 \pm 3.1 \mathrm{vs.} 22.2 \pm 17.1 \mathrm{pg} / \mathrm{mL}$, respectively; $P=0.0005)$. In culture, autologous MSCs $(n=11)$ secreted higher levels of SDF- $1 \alpha$ than allogeneic MSCs $(n=6)[76.0(63.7,100.9)$ vs. $22.8(7.2,43.5) \mathrm{pg} / \mathrm{mL}, P=0.0002]$. SDF- $1 \alpha$ and plasma TNF $\alpha$ negatively correlated with EPC-CFUs in both treatment groups $(R=-0.7$, $P=0.0004)$. ECs treated with 20 ng SDF-1 $\alpha$ expressed lower levels of TNF $\alpha$ mRNA than cells treated with $100 \mathrm{ng}(0.7 \pm 0.2$ vs. $2.1 \pm 0.3, P=0.0008)$. SDF- $1 \alpha$ at low but not high concentration inhibited the generation of ROS.

Conclusion: MSC secretion of SDF-1a inversely correlates with EPC-CFU production in DCM patients and therefore may be a modulator of MSC therapeutic effect in this clinical setting.

Clinical Trial Registration: https://clinicaltrials.gov/ct2/show/NCT01392625, identifier NCT01392625.

Keywords: endothelial dysfunction, mesenchymal stem cells, allogeneic, dilated cardiomyopathy, SDF $1 \alpha$

Abbreviations: DCM, dilated cardiomyopathy; EPC, endothelial progenitor cell; EPC-CFUs, endothelial progenitor cellcolony forming units; FMD, flow-mediated vasodilation; HF, heart failure; MSC, mesenchymal stem cell therapy; NAC, $\mathrm{N}$-acetyl-cysteine; SDF-1 $\alpha$, stromal derived factor- 1 alpha; TNF $\alpha$, tumor necrosis factor alpha. 


\section{INTRODUCTION}

Dilated cardiomyopathy (DCM) is the most prevalent type of non-ischemic cardiomyopathy (Go et al., 2014). DCM has a multifactorial etiology, no specific therapies (Felker et al., 2000; Hare, 2010), and is accompanied by impaired endothelial function and increased markers of inflammation (Roura and Bayes-Genis, 2009). Endothelial dysfunction - here defined as diminished flow-mediated vasodilation (FMD) and endothelial progenitor cell (EPC) function - produces a cascade of detrimental events, including decreased nitric oxide (NO) bioavailability, inadequate EPC circulation and function, and increased oxidative/nitrosative damage and inflammation, which places further hemodynamic stress on the failing myocardium (Cai and Harrison, 2000; Munzel et al., 2008).

Administration of mesenchymal stem cells (MSCs) is a regenerative therapy approach under investigation for both DCM and endothelial function (Hare et al., 2009, 2017; Karantalis and Hare, 2015; Karantalis et al., 2015). MSCs are anti-inflammatory, antifibrotic, and pro-angiogenic, and thus, are of particular interest for treating endothelial dysfunction in patients with DCM (Williams and Hare, 2011). We previously demonstrated that DCM patients have endothelial dysfunction characterized by fewer endothelial progenitor cell-colony forming units (EPC-CFUs) and reduced FMD (Premer et al., 2015). Endothelial function improved significantly 3 months after transendocardial injection of allogeneic MSCs, but not in patients that received autologous MSCs (Premer et al., 2015). Patients receiving allogeneic MSCs also had greater improvements in New York Heart Association (NYHA) functional classification and reduced major acute cardiac events (MACE), and hospitalization rates compared to those receiving autologous MSCs (Mushtaq et al., 2014; Hare et al., 2017). While these results are encouraging and have significant implications for the treatment of DCM, the mechanisms underlying the benefits of allogeneic MSCs require further study.

Mesenchymal stem cells exert many of their therapeutic effects via the release of paracrine factors, including stromal derived factor- $1 \alpha$ (SDF-1 $\alpha$ ), as well via the suppression of TNF $\alpha$ (Prockop and Youn Oh, 2012). We previously demonstrated that MSCs have an important role in cardiac stem cell migration, which is mediated through the SDF1/CXCR4 pathway (Hatzistergos Konstantinos et al., 2016). Additionally, it has been shown in vitro that there is an intimate relationship between $\mathrm{TNF} \alpha$ and SDF- $1 \alpha$ in cardiomyocyte mediated apoptosis (Jarrah et al., 2018). Accordingly, here we measured MSC secretion of SDF$1 \alpha$ and TNF $\alpha$ in vitro and plasma levels of TNF $\alpha$ in DCM patients that received MSC therapy to test the hypothesis that increased levels of SDF-1 $\alpha$ impair the MSC-mediated improvement of endothelial function and reduction of plasma TNFa 3-months post-injection.

Our study shows that autologous MSCs in culture secrete higher levels of SDF-1 $\alpha$ than do allogeneic MSCs. Importantly, patients that received autologous MSCs did not demonstrate improved endothelial function (Premer et al., 2015) or reduced plasma TNF $\alpha$, 3-months after cell therapy. In contrast, patients that received allogeneic MSCs had significantly reduced plasma TNF $\alpha$ levels, accompanied by improved endothelial function 3-months after cell therapy (Premer et al., 2015). We further studied the connection between SDF- $1 \alpha$ and oxidative/nitrosative stress in vitro and found that low concentrations of SDF- $1 \alpha$ inhibit the generation of mitochondrial ROS, hydrogen peroxide, and nitrotyrosine by ECs. These results suggest that secretion of high levels of SDF-1 $\alpha$ impair MSC efficacy, underlying the advantage allogeneic MSCs have relative to autologous cells for treatment of DCM.

\section{MATERIALS AND METHODS}

\section{Study Population}

All patients were recruited from POSEIDON-DCM (NCT01392625), "A Phase I/II, Randomized Pilot Study of the Comparative Safety and Efficacy of Transendocardial Injection of Autologous MSCs vs. Allogeneic Mesenchymal Stem Cells in Patients" with non-ischemic DCM, and enrolled as part of a University of Miami sub-study entitled "Studying Endothelial Function and Endothelial Progenitor Stem Cells' Colonies Before and After Heart Mesenchymal Stem Cell Transplantation" (endothelial trial \#20110543). POSEIDONDCM was a randomized clinical trial where patients received either 100 million autologous or allogeneic MSCs (Mushtaq et al., 2014; Hare et al., 2017). Autologous MSCs were harvested from the patient's bone marrow via an iliac crest aspiration, 4-6 weeks before cardiac catheterization (Mushtaq et al., 2014; Hare et al., 2017). Allogeneic MSCs were harvested from the bone marrow of healthy donors via iliac crest aspiration (Mushtaq et al., 2014; Hare et al., 2017). All MSC products were manufactured by the University of Miami Cell Manufacturing Program, as previously described (Hare et al., 2012; Da Silva and Hare, 2013). MSCs were characterized based on the expression of CD105 and the absence of CD45 (Hare et al., 2012; Da Silva and Hare, 2013).

\section{Cell Culture}

In order to measure MSC protein secretion, cryopreserved MSCs were rapidly thawed and plated on cell culture dishes in MSC medium (20\% fetal bovine plasma, $1 \%$ penicillin/streptomycin, and MEM alpha). Cell culture media was changed every other day and upon reaching $70 \%$ confluence, MSCs were cultured with serum-free medium for 24-h and medium collected, spin at 1200 RPM, aliquoted, and frozen until assessed by ELISA. In POSEIDON-DCM, allogeneic MSCs were obtained from 6 donors. Cells from only 4 of those donors were used to treat the 10 patients in this study. However, all 6 donor MSC lines were analyzed for SDF-1 $\alpha$. Additionally, autologous MSCs from 11 patients were analyzed.

In order to analyze the effect of SDF-1 $1 \alpha$ on ECs, human coronary artery endothelial cells (HCAECs) were grown to $70 \%$ confluency in tissue culture dishes. Cell culture media was changed every other day using EGM-2 BulletKit (Lonza CC-3162). HCAECs were then exposed to recombinant SDF$1 \alpha$ (Peprotech 300-28A). Additionally, cells were incubated 
with lipopolysaccharides (LPS; Sigma L4391) and subsequently treated with $20 \mathrm{ng}$ of SDF- $1 \alpha$.

\section{Plasma Collection}

Peripheral blood samples were obtained from each patient at baseline, and 3- and 6-months after MSC injection. Plasma was collected using a Ficoll-Paque density gradient and was subsequently frozen at $-80^{\circ} \mathrm{C}$ until use.

\section{Enzyme-Linked Immunosorbent Assays (ELISAs)}

Stromal derived factor- $1 \alpha$ and TNF $\alpha$ from conditioned medium were measured according to the provided protocol. Blood samples were obtained from 15 patients, 8 who received allogeneic MSCs, and 7 who received autologous. TNFa was measured in patient plasma at baseline, and 3-and 6-months post injection according to the provided protocol. No samples were diluted to increase sensitivity of the assay.

\section{Endothelial Function Measurement}

Endothelial progenitor cell-colony forming units were used to assess endothelial function and assays were performed as previously described (Premer et al., 2015). Briefly, EPCCFUs were determined by isolating EPCs from peripheral blood samples, plating them on 6-well fibronectin-coated dishes followed by 24-well fibronectin-coated dishes in CFU-Hill medium (Stem Cell Technologies, cat \#05900), and counting EPC-CFU formation on day five.

\section{Quantitative RT-PCR}

Total RNA was isolated from HCAECs using RNAeasy mini kit (Qiagen). RNA $(1 \mu \mathrm{g})$ was reverse-transcribed according to instructions utilizing a cDNA Synthesis kit (Applied Biosciences). Using Taqman Universal Master mix in an iQ5 real time PCR detection system (BioRad), qPCR was performed. All samples were run in duplicates and normalized to GAPDH Taqman gene-expression as follows: TNF1 $\alpha$ : Hs00174128_m1; NOS2: Hs01075529_m1; and GAPDH: Hs02758991_g1. The change in mRNA expression was calculated compared to the change in normalized GAPDH, and values were expressed as fold change over the control.

\section{Immunofluorescence Staining and Fluorescence Assisted Cell Sorting (FACS) Analysis}

Immunofluorescence staining was done on HCAECs cultured in EBM medium and plated onto LabTek $\mathrm{CC}^{2}$ chamber slides (Life Technologies). Various stimuli were applied to these cells: conditioned media from allogeneic MSCs, autologous MSCs and SDF-1 $\alpha(20 \mathrm{ng} / \mathrm{ml})$ (PeproTech). The cells were incubated for $1 \mathrm{~h}$ at $37^{\circ} \mathrm{C}$ and followed by stimulation with LPS $(1 \mathrm{mg} / \mathrm{ml})$ (Sigma-Aldrich) for $15 \mathrm{~m}$ at $37^{\circ} \mathrm{C}$. These were then stained with MitoSox (Life Technologies) for $30 \mathrm{~m}$ at $37^{\circ} \mathrm{C}$ followed by DAPI (Sigma-Aldrich) for $10 \mathrm{~m}$ at $37^{\circ} \mathrm{C}$. Specifically, cells were mounted onto glass slides with Mounting Medium Vectashield (Vector Laboratories). Images of cells were acquired using a Leica
LSM 710 confocal microscope with $63 \times$ objective, followed by measurement of the average cell area of at least 10 cells per field using ImageJ software.

Additionally, HCAECs cells were stimulated with the treatments mentioned above and additionally with a positive control, TBHP (50 mM) (Invitrogen), and two samples treated with $\mathrm{N}$-acetyl-cysteine (NAC, $250 \mathrm{mM}$ ) (Invitrogen) and LPS or TBHP, respectively. The cells were incubated for $3 \mathrm{~h}$ and further stimulated with NAC for $2 \mathrm{~h}$ and TBHP for $1 \mathrm{~h}$, all at $37^{\circ} \mathrm{C}$. These were then stained with DCF (Invitrogen) for $30 \mathrm{~m}$ and DAPI for $10 \mathrm{~m}$ at $37^{\circ} \mathrm{C}$. As an additional measurement of oxidative stress, HCAECs were incubated with cellROX deep-red reagent and measured by fluorescence assisted cell sorting (FACS) (Bone et al., 2013). Staining for ROS was performed by incubating cells at $37^{\circ} \mathrm{C}$ with $5 \mu \mathrm{M}$ CellROX Red reagent (C10491), following the manufacturer's protocols (Invitrogen), and directly analyzed without fixing. Cell analysis was performed in FACS Canto-II (BD Biosciences). For MFI determination, we used the flow cytometry analysis software FlowJo. MFI refers to the fluorescence intensity of each event (on average) of the selected cell population, in the chosen fluorescence channel.

The cells stained for nitrotyrosine were stimulated with the previous stimuli and incubated at room temperature with $4 \%$ PFA for $10 \mathrm{~min}$. The cells were blocked with 5\% BSA (Sigma-Aldrich) for $1 \mathrm{~h}$ and then incubated with a primary antibody against nitrotyrosine (1:500, Sigma-Aldrich) overnight. The slides were then coated with the corresponding secondary antibody for $1 \mathrm{~h}$. The cells were washed 3 times 5 min with PBS between every step and were further stained for DAPI for $10 \mathrm{~m}$ at $37^{\circ} \mathrm{C}$.

\section{Statistical Analysis}

To analyze the difference between autologous and allogeneic groups as well as to measure the difference before and after treatment in each group, an unpaired, two-tailed $t$-test was utilized. Correlations were measured using Pearson correlation, assuming a Gaussian distribution. Data are presented as mean and standard deviation of the mean. Both D'AgostinoPearson omnibus normality test and Shapiro-Wilk normality tests were run to measure within-group variability on all data (only significant differences were reported as Mann-Whitney). Differences between groups regarding baseline characteristics were analyzed using a Fisher exact test. A one-way ANOVA was used for qPCR experiments. Lastly, immunofluorescence experiments were analyzed using a Student's two-sided unpaired $t$-test with Welch's correction for two group comparisons and a one-way ANOVA for multiple comparisons where $p \leq 0.05$ was considered statistically significant.

\section{RESULTS}

\section{Baseline Characteristics}

A total of 21 DCM patients were analyzed for this study, 10 received allogeneic MSCs and 11 received autologous MSCs (Table 1). The mean age of injected patients was $55.8 \pm 11.2$ years and $65 \%$ were male. There were no differences between groups 
TABLE 1 | Baseline characteristics of patients with dilated cardiomyopathy $(n=21)$.

\begin{tabular}{|c|c|c|c|}
\hline \multirow[t]{2}{*}{ Baseline characteristics } & \multicolumn{2}{|c|}{ Cell type } & \multirow[t]{2}{*}{$P$-value } \\
\hline & Allogeneic $(n=10)$ & Autologous $(n=11)$ & \\
\hline Age at injection (years) & $58.3(7.82)$ & 55.909 (10.65) & 0.99 \\
\hline \multicolumn{4}{|l|}{ Gender } \\
\hline Male & $7(70 \%)$ & $6(54.5 \%)$ & 0.5 \\
\hline Female & $3(30 \%)$ & $5(45.5 \%)$ & 0.5 \\
\hline Ethnicity: Hispanic or Latino & $1(10 \%)$ & $6(54.5 \%)$ & $0.03^{*}$ \\
\hline Race: White & $8(80 \%)$ & $5(45.5 \%)$ & 0.1 \\
\hline Race: Black & $1(10 \%)$ & $0(0 \%)$ & 0.3 \\
\hline History of hypertension & $4(40 \%)$ & $2(18.2 \%)$ & 0.3 \\
\hline \multicolumn{4}{|l|}{ New York heart association class } \\
\hline Class I - No limitation & $2(20 \%)$ & $4(36.4 \%)$ & 0.4 \\
\hline Class II - Slight limitation of physical activity & $5(50 \%)$ & $6(54.5 \%)$ & 0.8 \\
\hline Class III - Marked limitation of physical activity & $3(30 \%)$ & $1(9.1 \%)$ & 0.2 \\
\hline History of congestive heart failure & $5(50 \%)$ & $5(45.5 \%)$ & 0.8 \\
\hline History of Valvular heart disease & $1(10 \%)$ & $0(0 \%)$ & 0.3 \\
\hline History of smoking & $7(70 \%)$ & $4(36.4 \%)$ & 0.3 \\
\hline History of diabetes & $0(0 \%)$ & $1(9.1 \%)$ & 0.3 \\
\hline Peak VO 2 (mL/kg/min) & $17.23 \pm 6.8$ & $15.91 \pm 5.94$ & 0.6 \\
\hline Six minute walk test (meters) & $437.78 m \pm 66.95$ & $425.27 \mathrm{~m} \pm 74.66$ & 0.7 \\
\hline Forced expiratory volume in one second (\%) & $2.43 \%(0.51)$ & $2.41 \%(0.9)$ & 0.9 \\
\hline MLHF: Median (IQR) & $44.6(24.75-68)$ & $39(21-67)$ & 0.6 \\
\hline \multicolumn{4}{|l|}{ LV size and function } \\
\hline Ejection fraction (\%) & $24.4 \% \pm 5.52$ & $21 \% \pm 7.68$ & 0.3 \\
\hline Left ventricular end diastolic volume (mL): Median (IQR) & $253.8 \mathrm{~mL}(225.2-272.45)$ & 193.2 mL (172.55-330.9) & 0.7 \\
\hline Left ventricular systolic volume (mL): Median (IQR) & 196.15 mL (171.73-219.95) & 164 mL (125.5-290.8) & 0.7 \\
\hline End diastolic diameter (cm): Median (IQR) & $7 \mathrm{~cm}(6.63-7.18)$ & $6.1 \mathrm{~cm}(5.85-7.65)$ & 0.9 \\
\hline \multicolumn{4}{|l|}{ Biomarkers } \\
\hline EPC-CFUs & $3 \pm 2$ colonies & $5 \pm 3$ colonies & 0.08 \\
\hline $\mathrm{TNF} \alpha$ & $24.5 \pm 5.6 \mathrm{pg} / \mathrm{mL}$ & $25.3 \pm 13.3 \mathrm{pg} / \mathrm{mL}$ & 0.9 \\
\hline
\end{tabular}

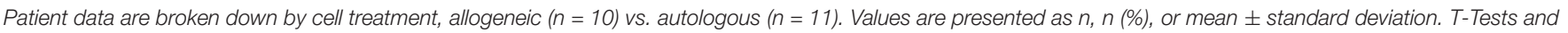
Chi-squared tests were used to compare groups, and statistically significant differences are indicated by bolding and an asterisk.

regarding gender, race and ethnicity, patient history, baseline ejection fraction, left ventricular end diastolic function, sixminute walk test, peak $\mathrm{VO}_{2}$, or Minnesota Living with heart failure (HF). Lastly, $\mathrm{TNF} \alpha$ plasma levels were similarly elevated at baseline in the two groups.

\section{Only Allogeneic MSCs Reduced Elevated Baseline TNF $\alpha$, Which Correlated With EPC-CFUs}

Given our previous findings that allogeneic MSCs improved endothelial function preferentially compared to autologous MSCs 3 months after administration (Premer et al., 2015), we investigated whether there was a differential inflammatory response since MSCs suppress inflammation (Prockop and Youn Oh, 2012), which in turn improves endothelial function (Shao et al., 2014). Accordingly, we measured plasma TNF $\alpha$ at baseline and 3-months after MSC infusion in patients with DCM. At baseline, patients $(n=15)$ had elevated levels of circulating $\mathrm{TNF} \alpha(24.8 \pm 10 \mathrm{pg} / \mathrm{mL})$, which was similar between patients receiving allogeneic $(n=8)$ vs. autologous $(n=7)$ MSCs
$(24.5 \pm 5.6$ vs. $25.3 \pm 13.3 \mathrm{pg} / \mathrm{mL}, P=\mathrm{NS}, T$-test $)$. Three months after allogeneic MSC treatment, TNF $\alpha$ levels declined from $24.5 \pm 5.6$ to $17.4 \pm 3.7 \mathrm{pg} / \mathrm{mL}(P=0.0005$; Figure 1A). In contrast, 3-months post-autologous MSCs treatment, TNF $\alpha$ levels were unchanged $(25.3 \pm 13.3$ to $42.4 \pm 33.1 \mathrm{pg} / \mathrm{mL}$, $P=$ NS; Figure 1B). There is a significant difference comparing the effect of allogeneic vs. autologous MSCs on the reduction of plasma TNF $\alpha 3$ months post treatment $(\Delta-7.1 \pm-1.9$ vs. $\Delta 17.1 \pm 19.8 \mathrm{pg} / \mathrm{mL}, P=0.009$; Figure 1C).

Next, we examined TNF $\alpha$ release from cultured allogeneic and autologous MSCs, and found them to be similar $(0.37 \pm 0.7$ vs. $0.1 \pm 0.2 \mathrm{pg} / \mathrm{mL}, P=\mathrm{NS}, T$-test; Figure $1 \mathrm{D})$. There was an inverse correlation between the change in plasma TNF $\alpha$ and the change in EPC colony formation from baseline to 3months post injection $(n=15)(R=-0.7, P=0.0004$, Pearson Correlation; Figure 1E), highlighting that a positive change in EPC-CFUs post-treatment was associated with a reduction in plasma TNF $\alpha$. These results suggest that the suppression of TNF $\alpha$ by allogeneic, but not autologous, MSCs plays a role in the mechanism mediating the beneficial effects of allogeneic MSC therapy in patients with DCM. 

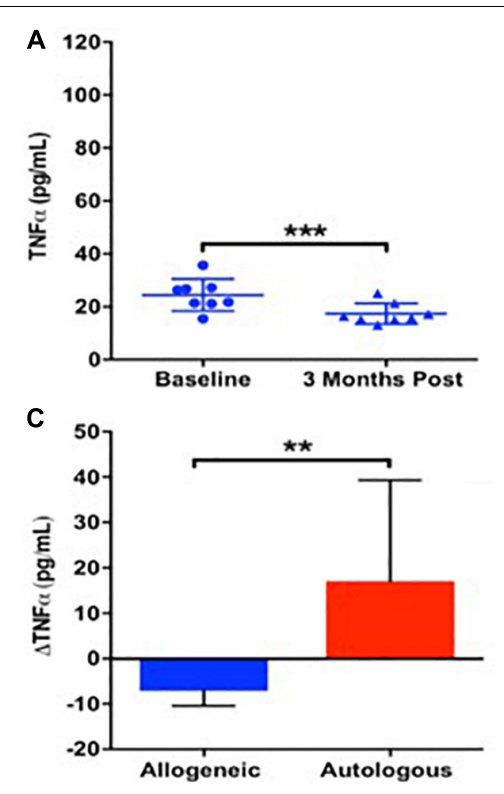

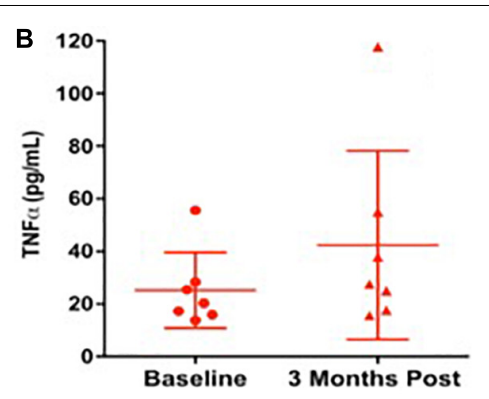

D

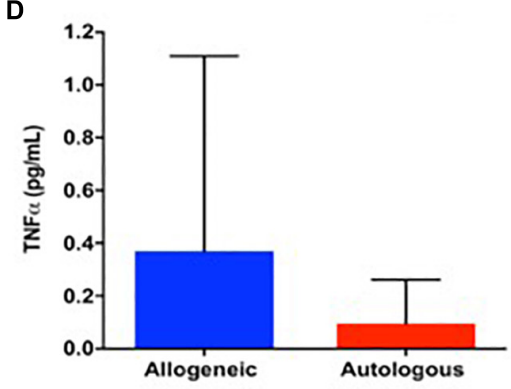

E

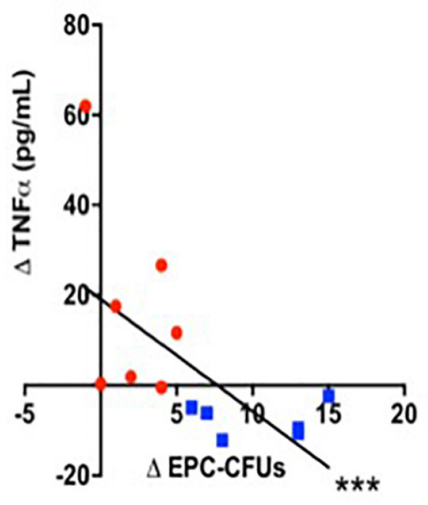

FIGURE 1 | The relationship between patient TNF $\alpha$ and endothelial colony formation at baseline and 3-months post autologous and allogeneic mesenchymal stem cell (MSC) treatment. (A) Patients who received allogeneic MSC treatment $(n=8)$ had a significant reduction in plasma TNF $\alpha$ from baseline to 3 months post treatment ( $24.5 \pm 5.6$ to $\left.17.4 \pm 3.7 \mathrm{pg} / \mathrm{mL}, P=0.0005^{* * *}\right)$. (B) Patients who received autologous MSC treatment $(n=7)$ had no change in plasma TNF $\alpha$ from baseline to 3 months post injection ( $25.3 \pm 13.3$ to $42.4 \pm 33.1 \mathrm{pg} / \mathrm{mL}, P=\mathrm{NS}$ ). (C) There is a significant difference comparing the effect of allogeneic vs. autologous on the reduction of plasma TNF $\alpha 3$ months post treatment ( $\Delta-7.1 \pm-1.9 \mathrm{vs.} \Delta 17.1 \pm 19.8 \mathrm{pg} / \mathrm{mL}, P=0.009 * *)$. (D) Neither allogeneic nor autologous MSCs are secreting notable levels of TNF $\alpha(0.37 \pm 0.7$ vs. $0.1 \pm 0.2 \mathrm{pg} / \mathrm{mL}, P=\mathrm{NS})$. (E) There was a significant correlation between the change in plasma TNF $\alpha$ and the change in EPC colony formation from baseline to 3-months post injection $(n=15)\left(R=-0.7, P=0.0004^{* * *}\right)$.

\section{SDF-1 $\alpha$ Modulates Endothelial Function}

We next examined SDF1 $\alpha$ levels, because this cytokine promotes mobilization of EPCs via the SDF-1/CXCR4 axis (Kijowski et al., 2001; Floege et al., 2009; Figure 2A). We measured SDF$1 \alpha$ release into serum-free culture medium by allogeneic and autologous MSCs. Autologous MSCs $(n=11)$ secreted 3.3 fold higher levels of SDF-1 $\alpha$ compared to allogeneic MSCs $(n=6)$ [76.0 $(63.7,100.9)$ vs. $22.8(7.2,43.5) \mathrm{pg} / \mathrm{mL}, P=0.0005$, $T$-test; Figure 2B]. Subsequently, we examined the relationship between SDF- $1 \alpha$ release in vitro and the change in EPC-CFUs in vivo from baseline to 3-months post MSC treatment and observed a significant inverse correlation between MSC SDF- $1 \alpha$ secretion and the change in EPC-CFUs $(n=21, R=-0.7, P=0.0004$, Pearson Correlation; Figure 2C). Notably, patients receiving allogeneic MSCs had an increased number of EPC-CFUs posttreatment. Similarly, there was a correlation between the amount of SDF- $1 \alpha$ secretion from cultured MSCs and the change in TNF $\alpha$ from baseline to 3 -months post injection $(n=15)(R=0.7$, $P=0.003$, Pearson Correlation; Figure 2D). These results suggest that high levels of SDF-1 $\alpha$ impair MSC efficacy, negatively correlating to both EPC-CFUs and TNF $\alpha$.

\section{SDF- $1 \alpha$ Levels Modulate the Amount of Endothelial Cell TNF $\alpha$ Expression}

We further tested the link between SDF- $1 \alpha$, TNF $\alpha$, and ECs in vitro. Human coronary artery endothelial cells (HCAECs) exposed to low levels of recombinant SDF-1 $\alpha$ (20 ng) expressed low levels of TNF $\alpha$ mRNA $(0.7 \pm 0.2)$, whereas HCAECs exposed to high levels of recombinant SDF-1 $\alpha$ (100 ng) expressed high levels of TNF $\alpha(2.1 \pm 0.3, p=0.0008$ between groups, ANOVA; Figure 3A). Furthermore, cells treated with 100 ng SDF-1 $\alpha$ produced significantly higher levels of TNF $\alpha$ compared to cells treated with PBS, whereas cells treated with 20 ng SDF- $1 \alpha$ had similar TNF $\alpha$ levels as PBS-treated cells. This result suggests that high levels of SDF-1 $\alpha$ increase TNF $\alpha$ mRNA in ECs.

We next tested if low levels of SDF- $1 \alpha$ reduce TNF $\alpha$ upregulation in response to LPS in vitro. We incubated HCAECs with LPS to induce an immune response and subsequently treated cells with $20 \mathrm{ng}$ SDF- $1 \alpha$. There was a significant increase in TNF $\alpha$ mRNA after treatment with LPS $(\Delta 11.3 \pm 3, p=0.001$, ANOVA), and $20 \mathrm{ng}$ SDF- $1 \alpha$ counteracted this increase $(\Delta-4.8 \pm 1.6$, $p=0.03$, ANOVA; Figure 3B). These results demonstrate that SDF- $1 \alpha$ modulates the expression of TNF $\alpha$ in ECs in vitro. Notably, these results highlight the observed allogeneic over autologous advantage, where allogeneic MSCs - which produce low levels of SDF- $1 \alpha$ - and autologous MSCs - which produce high levels of SDF-1 $\alpha$ - differentially effect TNF $\alpha$ in patients 3 months post treatment.

\section{SDF-1 $\alpha$ Is Protective Against Both Mitochondrial Reactive Oxygen Species (ROS) and Nitrosative Stress}

Oxidative stress initiates a wide array of deleterious processes that contribute to endothelial dysfunction. Therefore, we investigated 
A

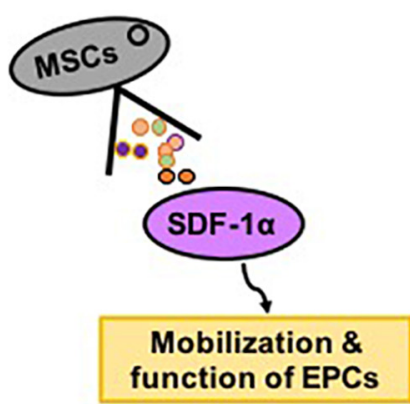

C

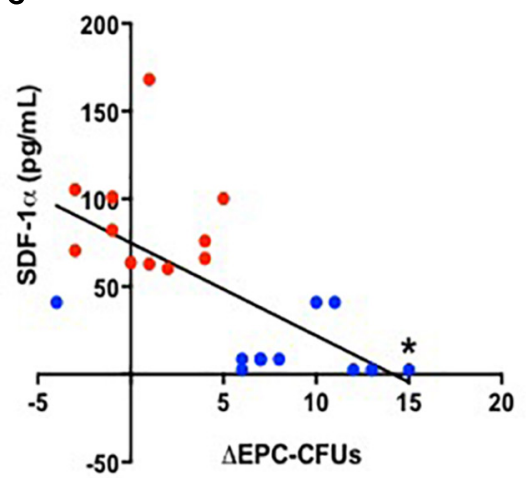

B

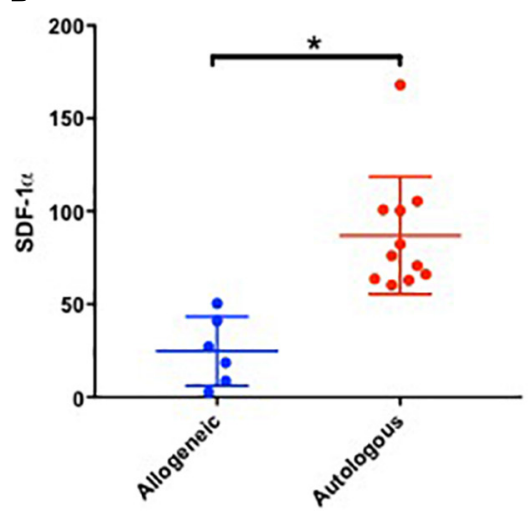

D

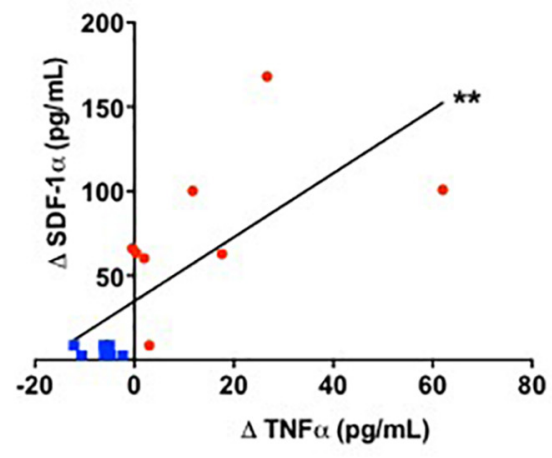

FIGURE 2 | Stromal derived factor-1 $\alpha$ (SDF-1 $\alpha$ ) as a biomarker for endothelial function. (A) Schematic illustrating that mesenchymal stem cells (MSCs) secrete SDF-1 $\alpha$ which stimulates the mobilization and function of endothelial progenitor cells (EPCs). (B) Allogeneic MSCs $(n=6)$ secrete significantly lower levels of SDF-1 $\alpha$ compared to autologous MSCs $(n=11) 22.8(7.2,43.5)$ vs. $\left.76.0(63.7,100.9) \mathrm{pg} / \mathrm{mL}, P=0.0005^{*}\right)$. (C) There was a significant inverse correlation between MSC SDF-1 $\alpha$ secretion and the change in EPC-CFUs from baseline to 3-months post injection $\left(n=21, R=-0.7, P=0.0004^{*}\right)$. (D) Additionally, there was a correlation between the amount of SDF-1 $\alpha$ secretion from cultured MSCs and the change in TNF $\alpha$ from baseline to 3-months post injection compared to $(n=15)(R=0.7$, $\left.P=0.003^{* *}\right)$.

whether SDF- $1 \alpha$ and MSC conditioned medium, which contains SDF- $1 \alpha$, could prevent ROS production in ECs.

Human coronary artery endothelial cells were pre-treated with either low dose recombinant SDF-1 $\alpha(n=4)$, or allogeneic MSC- $(n=4)$, or autologous MSC-conditioned medium $(n=5)$, then stimulated with LPS for $6 \mathrm{~h}$, and subsequently incubated with cell permeable probes sensitive to superoxide (MitoSOX Red) or hydrogen peroxide $\left(\mathrm{H}_{2} \mathrm{O}_{2} ; \mathrm{H} 2-\mathrm{DCF}-\mathrm{DA}\right)$. MitoSox red, a mitochondrial superoxide indicator, was used to label specifically mitochondrial superoxide followed by DAPI (nuclei dye) in HCAECs. Images were captured by confocal microscopy. As expected, LPS significantly increased superoxide production compared to control (301676 \pm 7843 vs. $112664 \pm 22307$, $p<0.0001$, ANOVA; Figures 4A,B). Low dose SDF-1 $\alpha$, allogeneic MSC conditioned medium, and autologous MSC conditioned medium prevented superoxide production induced by LPS $(58674 \pm 8145,52665 \pm 33625,39535 \pm 13687 \mathrm{AU}$, $p<0.0001$, respectively, ANOVA; Figures 4A,B).

We next looked at $\mathrm{H}_{2} \mathrm{O}_{2}$ production rates using DCF-DA, and again found that LPS induced markedly higher rates of $\mathrm{H}_{2} \mathrm{O}_{2}$ production compared to control (22491 \pm 16371 vs. $4464 \pm 2047$, $p<0.0001$, ANOVA), while low dose SDF-1 $\alpha$, allogeneic MSC conditioned medium, and autologous MSC conditioned medium attenuated cell $\mathrm{H}_{2} \mathrm{O}_{2}$ production $(6172 \pm 3920 \mathrm{AU}, p<0.01$, $9753 \pm 4751 \mathrm{AU}, p<0.05,46941 \pm 89798, p<0.05$, respectively, ANOVA; Figures 4C,D).

To lend further confidence to our results, we measured ROS by an alternative method, flow cytometry (Supplementary Figure S1A). HCAECs were incubated with cellROX deepreagent and measured by FACS. We observed that HCAECs pre-treated with low dose SDF- $1 \alpha$, allogeneic MSC conditioned media, or autologous MSC conditioned media lowered TBHPinduced ROS production by 50,33 , and $30 \%$, respectively. These results are consistent with those observed above.

Next, we measured the effect of SDF- $1 \alpha$ and MSC conditioned medium on nitrotyrosine levels, a biomarker of reactive nitrogen species formation and an indicator of protein oxidative damage (Figures 4E,F). LPS significantly increased nitrotyrosine expression (75894 \pm 13874 vs. $43546 \pm 10020 \mathrm{AU}, p<0.001$, ANOVA; Figures 4E,F). Interestingly, only low dose SDF- $1 \alpha$ and allogeneic MSC conditioned medium decreased nitrotyrosine expression $(52132 \pm 4395 \mathrm{AU}, p<0.05,34761 \pm 4898 \mathrm{AU}$, 


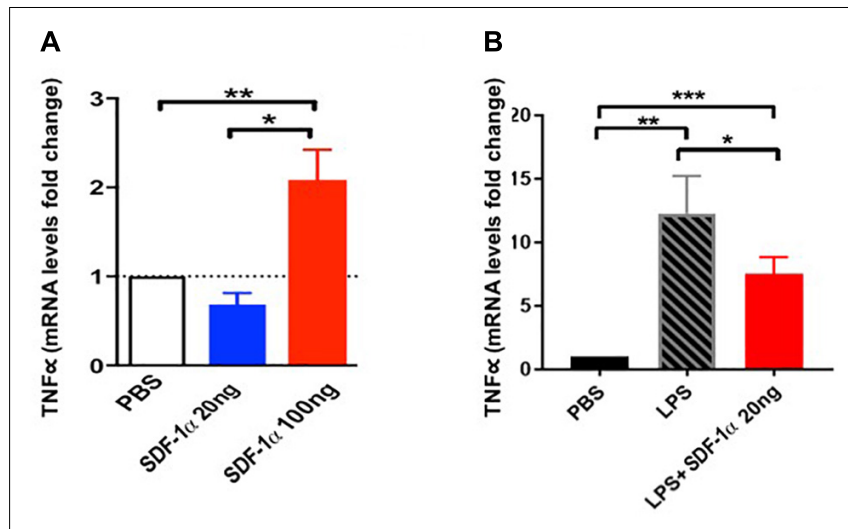

FIGURE 3 | Stromal derived factor- $1 \alpha$ levels modulate the expression of TNF $\alpha$ expression in human coronary artery endothelial cells (HCAECs). (A) HCAECs exposed to low levels ( $20 \mathrm{ng}$ ) of SDF- $1 \alpha$ express low levels of TNF $\alpha$ mRNA $(0.7 \pm 0.2)$ comparable to the PBS control, whereas those exposed to high levels (100 ng) express high levels of TNF $\alpha$ mRNA compared to control $\left(2.1 \pm 0.3, p=0.005^{* *}\right)$. Furthermore, there is a significant difference comparing low dose vs. high dose $\left(p=0.004^{*}\right)$ as well as comparing all three groups together $(p=0.0008)$. (B) HCAECs stimulated with lipopolysaccharide (LPS) significantly upregulate TNF $\alpha \operatorname{mRNA}\left(\Delta 11.3 \pm 3, p=0.001^{* *}\right)$, and low dose (20 ng) of SDF-1 $\alpha$ attenuate this elevation $\left(\Delta-4.8 \pm 1.6, p=0.03^{*}\right)$. $* * * p<0.01$.

$p<0.0001$, respectively, ANOVA; Figures 4E,F). Autologous MSC conditioned medium did not block LPS induced nitrotyrosine expression $(56949 \pm 21648$ vs. $75894 \pm 13874$, respectively, $p=$ NS; Figures $4 \mathrm{E}, \mathbf{F}$ ).

In order to further validate our nitrotyrosine experiment, we checked the mRNA levels of iNOS (NOS2). Pathologic nitric oxide production by iNOS can be the source of nitrosative stress. We performed a curve dose response to SDF- $1 \alpha$ in HCAECs stimulated with LPS. Low amounts of SDF1 $\alpha$ were able to downregulate the increased mRNA levels of NOS2 stimulated by LPS treatment $(4.07 \pm 0.03$ vs. $9.85 \pm 1.62$, $p<0.01$, ANOVA), however, higher amounts of SDF1 $\alpha$ did not change NOS2 mRNA levels (Supplementary Figure S1B). Together, these findings demonstrate that low (physiological) amounts of SDF-1 $\alpha$ may serve a protective role against ROS and nitrosative stress, which mechanistically underlie endothelial dysfunction.

\section{DISCUSSION}

The major new findings of this study are that autologous MSCs secrete higher levels of SDF-1 $\alpha$ in vitro than allogeneic MSCs, and that these levels inversely correlate with EPC bioactivity in DCM patients. Three months after infusion, DCM patients that received autologous MSCs had no improvement in plasma TNF $\alpha$ levels. In contrast, patients that received allogeneic MSCs had reduced TNF $\alpha$ plasma levels. Furthermore, in vitro, SDF-1 $\alpha$ at low concentration offset mitochondrial ROS and nitrosative stress. Based on our previous observations that allogeneic, but not autologous, MSCs improve endothelial function as measured by EPC-CFU formation and FMD\% (Mushtaq et al., 2014;
Premer et al., 2015; Hare et al., 2017), together with the findings presented here, we propose that the elevated levels of SDF-1 $\alpha$ inhibit the beneficial effects of MSCs. Allogeneic MSCs obtained from young, healthy donors secreted lower levels of SDF- $1 \alpha$ in vitro, which correlated with reduction of $\mathrm{TNF} \alpha$ and improved endothelial function, as indexed by increasing EPC-CFUs and FMD, in DCM patients (Figure 5).

Patients with DCM present with endothelial dysfunction as measured by reduced EPC-CFUs and impaired FMD. Many clinical trials have established the beneficial effects of MSCs in HF (Hare et al., 2009, 2012, 2017; Mushtaq et al., 2014; Karantalis and Hare, 2015; Kanelidis et al., 2016), due at least in part to paracrine effects. However, there is a paucity of studies identifying the specific factors secreted by MSCs responsible for these effects, as well as few studies addressing the DCM patient population. In vitro studies show that MSCs secrete anti-inflammatory factors and cytokines, such as IL-2, TGF$\beta 1$, hepatocyte growth factor, nitric oxide (NO), prostaglandin 2 , and SDF- $1 \alpha$, that can modulate the mobilization of EPCs from bone marrow (Iyer and Rojas, 2008; Karantalis and Hare, 2015). Furthermore, MSCs stimulate angiogenesis and vasculogenesis, as well as suppress inflammation (Williams and Hare, 2011). However, no studies have identified the mechanisms underlying MSC efficacy and demonstrated the effect on endothelial function in a clinical model. Here we examined MSCs from patients enrolled in the POSEIDONDCM clinical trial, along with various circulating factors and parameters of endothelial function, to gain novel insights into the differential effect of autologous vs. allogeneic MSCs on endothelial function. We previously showed that patients in the POSEIDON-DCM clinical trial who received allogeneic MSCs had improved endothelial function, whereas patients who received autologous MSCs did not (Premer et al., 2015). Furthermore, we showed that only cell culture medium from allogeneic MSCs was able to restore endothelial tube networks that were impaired by treatment with the nitric oxide inhibitor, L-NG-Nitroarginine methyl ester $\mathrm{N}$ omega-Nitro-L-arginine methyl ester hydrochloride (L-NAME) ${ }^{5}$. These findings led us to explore the role of SDF- $1 \alpha$ in mediating these effects due to its previously described role in stimulating EPC function, EPC migration, and vasculogenesis (Petit et al., 2007). Notably, here we demonstrated an important and novel cytokine that could explain, at least in part, the differences between autologous and allogeneic MSC therapy in these patients. We showed that allogeneic MSCs secrete significantly lower levels of SDF$1 \alpha$ than autologous MSCs in vitro, which was associated with reduced systemic $\mathrm{TNF} \alpha$ and increased EPC bioactivity in patients, thereby improving arterial physiologic vasodilatory response and decreasing unfavorable cytokine mobilization, 3months post injection.

Delineating the interplay between SDF- $1 \alpha$ and $\mathrm{TNF} \alpha$ is an emerging area of research regarding EC function. Classically, SDF-1 $\alpha$ signaling has positive effects on stem cell homing, stimulating EPC circulation, and enhancing neovascularization (Askari et al., 2003; Wojakowski et al., 2008). However, we found a paradoxical effect in which very high levels of SDF-1 $\alpha$ secretion by autologous MSCs in vitro was associated with an 

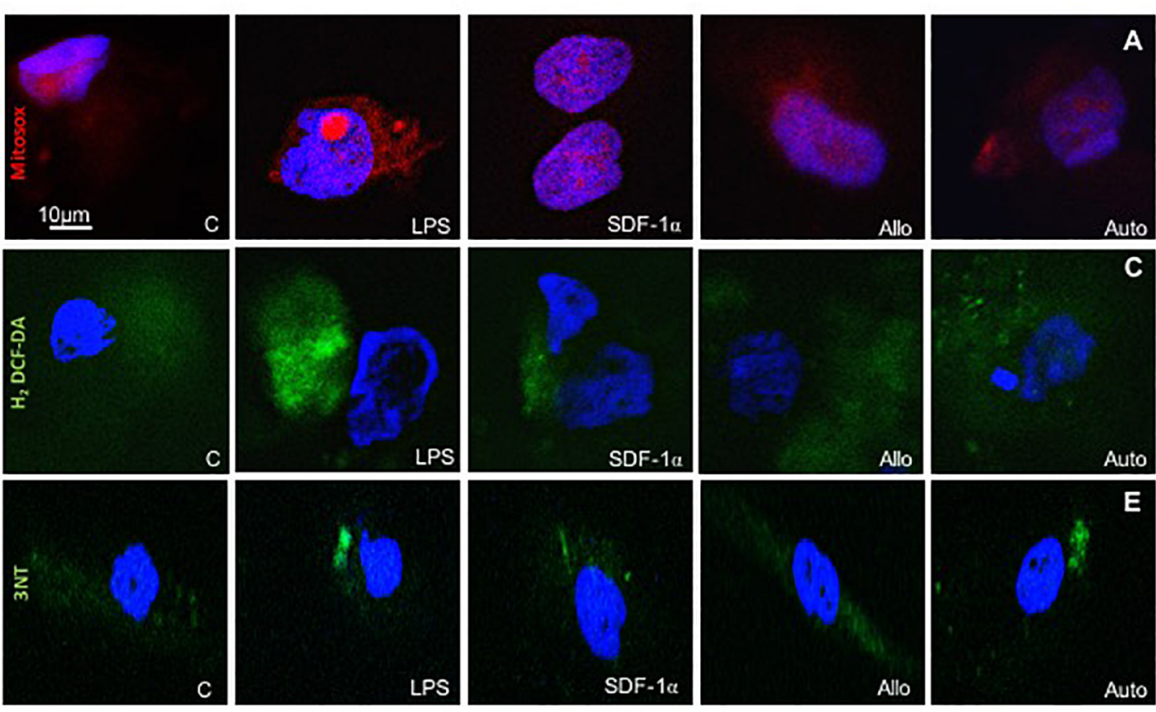

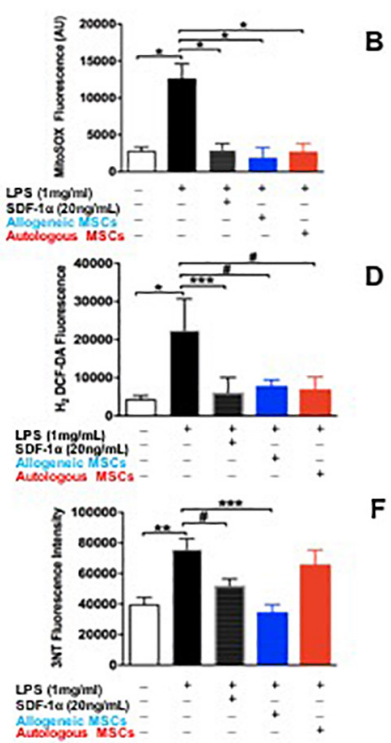

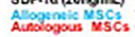

FIGURE 4 | Low dose SDF-1 $\alpha$ is protective against both mitochondrial reactive oxygen species (ROS) AND nitrosative stress. (A) Representative

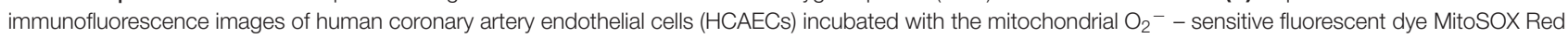
(10 um), and DAPI (blue) after treatment with SDF-1 $\alpha$ recombinant (20 ng; $n=4)$, allogeneic MSC conditioned medium ( $n=4)$ or autologous MSC conditioned medium ( $n=5$ ) and stimulated with LPS (1 ug/mL). (B) Quantification of MitoSOX Red fluorescence showed that LPS significantly increased superoxide production compared to control (301676 \pm 7843 vs. $\left.112664 \pm 22307, p<0.0001^{*}\right)$, whereas SDF-1 $\alpha$, allogeneic MSC conditioned medium, and autologous MSC conditioned medium prevented superoxide production induced by LPS (58674 $\pm 8145,52665 \pm 33625,39535 \pm 13687 \mathrm{AU}$, $p<0.0001 *$, respectively. (C) Representative immunofluorescence images via confocal microscopy of HCAECs incubated with $\mathrm{H}_{2}$-DCF-DA (Green) that detects intracellular peroxides including $\mathrm{H}_{2} \mathrm{O}_{2}$ and $\mathrm{DAPI}$ (blue). (D) Quantification of the average of DCF fluorescence showing LPS induced significantly higher rates of hydrogen peroxide production compared to control ( $22491 \pm 16371$ vs. $\left.4464 \pm 2047, p<0.0001^{*}\right)$, while SDF-1 $\alpha$, allogeneic MSC conditioned medium, and autologous conditioned medium attenuated cell hydrogen peroxide production (6172 $\pm 3920 \mathrm{AU}, p<0.01^{* * *}, 9753 \pm 4751 \mathrm{AU}, p<0.05^{\#}, 46941 \pm 89798, p<0.05^{\#}$, respectively). (E) Representative pictures of nitrotyrosine (3NT) expression in HCAECs stimulated with LPS followed by SDF-1 $\alpha$, allogeneic MSC conditioned medium, and autologous conditioned medium. (F) Quantification of 3NT fluorescence demonstrating that LPS significantly increased nitrotyrosine expression (75894 \pm 13874 vs. $43546 \pm 10020$ AU, $p<0.001 * *$, and only SDF-1 $\alpha$ and allogeneic MSC conditioned medium reduced nitrotyrosine expression (52132 $\left.\pm 4395 \mathrm{AU}, p<0.05^{\#}, 34761 \pm 4898 \mathrm{AU}, p<0.0001^{* * *}\right)$. Autologous MSC conditioned medium did not block LPS induced nitrotyrosine expression (56949 \pm 21648 vs. $75894 \pm 13874$, respectively, $p=$ NS).

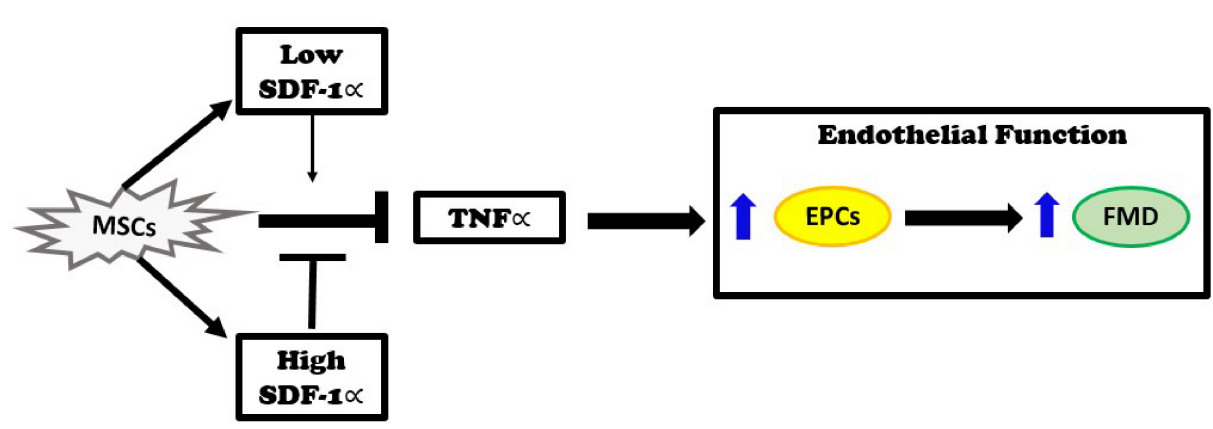

FIGURE 5 | Injection of MSCs into patients with dilated cardiomyopathy reduces elevated TNF $\alpha$ levels and improves endothelial function as measured by an improvement in endothelial progenitor cell (EPC) colonies and flow-mediated vasodilation (FMD). These effects remain intact when SDF-1 $\propto$ levels are low. On the other hand, when SDF- $1 \alpha$ levels are high, the beneficial effects of MSCs are inhibited.

increase in the already elevated levels of TNF $\alpha$ in DCM patients, ultimately offsetting positive effects on endothelial function. In agreement with this concept, Han et al. showed that SDF- $1 \alpha$ activates NF-kB, which in turn stimulates $\mathrm{TNF} \alpha$ production, inducing cell death in primary astrocytes (Han et al., 2001). Similarly, it was recently reported that high doses of SDF- $1 \alpha$ induce $\mathrm{TNF} \alpha$-mediated apoptosis in adult rat cardiomyocytes and that this effect is dose dependent, with lower doses appearing to be protective against basal cell death (Jarrah et al., 2018). Shibata et al. (2013) also illustrated the negative effects of SDF$1 \alpha$ overexpression, which results in gastric dysplasia in which inflammation is greatly accelerated. Ultimately, these studies are consistent with our MSC findings, in which autologous MSCs secreted elevated levels of SDF- $1 \alpha$ resulting in detrimental 
effects on inflammation as measured by plasma concentrations of TNF $\alpha$.

Furthermore, TNF $\alpha$ contributes significantly to pathologic inflammation and vascular dysfunction (Feldman et al., 2000; Zhang et al., 2009) and is elevated in patients with DCM (Feldman et al., 2000; Ridker et al., 2000). However, our study is the first to demonstrate that MSCs isolated from healthy donors reduced these circulating pathologic levels 3 months post injection, while MSCs isolated from patients with DCM had no effect on reducing $\mathrm{TNF} \alpha$ levels. In our recent report of the primary findings of POSEIDON-DCM (Hare et al., 2017), we examined TNF $\alpha$ levels 6 months post allogeneic and autologous MSC administration. Interestingly, we found that both treatments reduced elevated $\mathrm{TNF} \alpha$, however, allogeneic MSCs were twice as effective at reducing these levels. This result suggests that there is an attenuated response to autologous MSC cell therapy, at 3 months there is no reduction, while at 6 months there is a small reduction (Hare et al., 2017). Tögel et al. (2005) illustrated that patients with kidney disease who received MSCs were protected against ischemic renal failure via a paracrine mechanism mediated by reducing TNF $\alpha$, IL$1 \beta$, and IFN $-\gamma^{33}$, paralleling our results in DCM patients. In addition, we have shown in an elderly frail population that intravenous infusion of allogeneic MSCs decreases TNF $\alpha$ plasma levels and improves physical performance measures and quality of life (Golpanian et al., 2017; Tompkins et al., 2017). Moreover, in the current study, TNF $\alpha$ levels correlated with SDF- $1 \alpha$ and EPC-CFUs, providing mechanistic insight. In line with these findings, Hong et al. (2015) found that TNF $\alpha$ down-regulated EPC expression resulting in reduced numbers of EPC-CFUs as well as diminished incorporation into HUVEC networks in children with vasculitis.

There are several limitations to our study, which is part of a clinical trial. Cytokine experiments were done in vitro, and the association between SDF- $1 \alpha, \mathrm{TNF} \alpha$, and EPC-CFUs was based on robust correlations combined with the known signaling pathway for SDF-1 $\alpha$ (Kijowski et al., 2001). Notably, our in vitro EC experiments in which recombinant SDF$1 \alpha$ modulated the expression of TNF $\alpha$ lend confidence to our conclusions. Furthermore, previous studies support our findings. Specifically, the role of SDF-1 $\alpha$ in reducing oxidative stress in vivo has been demonstrated in a number of murine studies. Blocking the SDF-1 $\alpha$ receptor with ADM3100 in mice receiving LPS resulted in increased oxidative stress in a variety of organs, as compared to mice receiving LPS alone (Seemann and Lupp, 2016). Indeed, administration of an SDF$1 \alpha$ analog (CTCE-0214D) showed antioxidative properties by increasing the expression and activity of heme oxygenase 1 (HO-1), an antioxidant enzyme (Seemann and Lupp, 2016). In addition, it has been shown that high levels of ROS lead to EC dysfunction and death (Irani, 2000; Panth et al., 2016) by damaging macromolecules, decreasing NO bioavailability (Godo and Shimokawa, 2017), and inhibiting release of endotheliumderived hyperpolarizing factors (EDHF) (Eizawa et al., 1995; Godo and Shimokawa, 2017). Zhang et al. (2016) reported that SDF- $1 \alpha$ has a direct rescue effect on oxidative stress limiting ROS generation at the mitochondrial level. Dinić et al. (2016) showed that SDF- $1 \alpha$ protects pancreatic $\beta$-cells from the toxic effects of $\mathrm{H}_{2} \mathrm{O}_{2}$ by enhancing CAT activity and expression. Another limitation to our study is that a cytokine panel was run on 3 patients in order to choose cytokines on which to focus. Future studies will aim to delineate the difference between allogeneic and autologous MSCs through large-scale secretome analysis. Moreover, the number of patients in this study was relatively small, while there were 21 patient samples for EPC-CFUs and SDF- $1 \alpha$ analysis, only 15 of those patients had blood samples available for TNF $\alpha$ analysis. Nonetheless, the differences between allogeneic and autologous MSC treatment outcomes were striking, lending confidence to the results. Patients who received autologous MSCs had a bone marrow aspiration prior to injection, while patients who received allogeneic MSCs did not. Although this extra intervention may have caused a minor acute inflammatory response, patients did not receive cells until 4-6 weeks after the aspiration to ensure recovery; therefore, it should have little to no impact on the results. Lastly, we were not able to investigate whether cells delivered to the heart can be found in the circulation of these patients.

Ultimately, this study demonstrates a potent and clinically relevant efficacy outcome of transendocardial injection of MSCs in patients with DCM. Allogeneic MSCs secreted lower levels of SDF-1 $\alpha$ in vitro than autologous MSCs, which correlated with changes in plasma $\mathrm{TNF} \alpha$ levels in DCM patients treated with MSCs. As impairment in the endothelial function of patients with cardiovascular disease is known to be highly predictive of adverse outcomes and disease progression, targeting endothelial function represents an important therapeutic strategy. Together, these findings reveal a mechanism mediating the effects of MSCs on endothelial function and have important implications for the use of allogeneic and autologous MSCs in patients with DCM.

\section{DATA AVAILABILITY}

All datasets for this study are included in the manuscript and the Supplementary Files.

\section{ETHICS STATEMENT}

The studies involving human participants were reviewed and approved by the University of Miami, IRB. The patients/participants provided their written informed consent to participate in this study.

\section{AUTHOR CONTRIBUTIONS}

$\mathrm{CP}$, IS, and JH contributed to the conception and design of the study. CP, VP, AW, TL-H, and RS performed the experiments and data collection. $\mathrm{CP}$ and $\mathrm{WB}$ performed the statistical analysis. $\mathrm{CP}$ wrote the first draft of the manuscript. IS, WB, CD, and JH wrote 
the sections of the manuscript. All authors contributed to the manuscript revision, read, and approved the submitted version.

\section{FUNDING}

CP was supported by the American Heart Association (AHA) Pre-doctoral Fellowship 15PRE25730025 and the National Institute of Health (NIH) grant R01 HL RO110737 to JH. JH and IS were supported by the NIH grants 1R01 HL134558, 5UM 1HL113460, and R01 HL137355. JH was also supported by the NIH grant R01 HL107110 and the Starr and Soffer Family Foundations.

\section{REFERENCES}

Askari, A. T., Unzek, S., Popovic, Z. B., Goldman, C. K., Forudi, F., Kiedrowski, M., et al. (2003). Effect of stromal-cell-derived factor 1 on stem-cell homing and tissue regeneration in ischaemic cardiomyopathy. Lancet 362, 697-703. doi: 10.1016/s0140-6736(03)14232-8

Bone, B., Seredick, B., and Olszowy, M. (2013). Reactive oxygen probes - a broad range of colors with easier labeling and compatibility with fixation: novel CellROX ${ }^{\circledR}$ reagents from molecular probes ${ }^{\circledR}$ (P3295). J. Immunol. 190:211.5.

Cai, H., and Harrison, D. G. (2000). Endothelial dysfunction in Cardiovascular Diseases: the role of oxidant stress. Circ. Res. 87, 840-844. doi: 10.1161/01.res. 87.10 .840

Da Silva, J. S., and Hare, J. M. (2013). "Cell-based therapies for myocardial repair: emerging role for bone marrow-derived mesenchymal stem cells (MSCs) in the treatment of the chronically injured heart," in Wound Regeneration and Repair: Methods and Protocols, eds R. G. Gourdie and T. A. Myers (Totowa, NJ: Humana Press), 145-163. doi: 10.1007/978-1-62703-505-7_8

Dinić, S., Grdović, N., Uskoković, A., Đorðević, M., Mihailović, M., Jovanović, J. A., et al. $(20$ 16). CXCL12 protects pancreatic $\beta$-cells from oxidative stress by a Nrf2-induced increase in catalase expression and activity. Proc. Jpn. Acad. Ser. B Phys. Biol. Sci. 92, 436-454. doi: 10.2183/pjab.92.436

Eizawa, H., Yui, Y., Inoue, R., Kosuga, K., Hattori, R., Aoyama, T., et al. (1995). Lysophosphatidylcholine inhibits endothelium-dependent hyperpolarization and $\mathrm{N} \omega$-Nitro-l-arginine/indomethacinresistant endothelium-dependent relaxation in the porcine coronary artery. Circulation 92, 3520-3526. doi: 10.1161/01.cir.92.12.3520

Feldman, A. M., Combes, A., Wagner, D., Kadakomi, T., Kubota, T., You Li, Y., et al. (2000). The role of tumor necrosis factor in the pathophysiology of heart failure. J. Am. Coll. Cardiol. 35, 537-544.

Felker, G. M., Thompson, R. E., Hare, J. M., Hruban, R. H., Clemetson, D. E., Howard, D. L., et al. (2000). Underlying causes and long-term survival in patients with initially unexplained cardiomyopathy. N. Engl. J. Med. 342, 1077-1084. doi: 10.1056/nejm200004133421502

Floege, J., Smeets, B., and Moeller, M. J. (2009). The SDF-1/CXCR4 axis is a novel driver of vascular development of the glomerulus. J. Am. Soc. Nephrol. 20, 1659-1661. doi: 10.1681/asn.2009060621

Go, A. S., Mozaffarian, D., Roger, V. L., Benjamin, E. J., Berry, J. D., Blaha, M. J., et al. (2014). Heart Disease and Stroke Statistics-2014 Update. Rep. Am. Heart Assoc. 129, e28-e292.

Godo, S., and Shimokawa, H. (2017). Divergent roles of endothelial nitric oxide synthases system in maintaining cardiovascular homeostasis. Free Radic. Biol. Med. 109, 4-10. doi: 10.1016/j.freeradbiomed.2016.12.019

Golpanian, S., DiFede, D. L., Khan, A., Schulman, I. H., Landin, A. M., Tompkins, B. A., et al. (2017). Allogeneic human mesenchymal stem cell infusions for aging frailty. J. Gerontol. A Biol. Sci. Med. Sci. 72, 1505-1512. doi: 10.1093/gerona/ glx056

Han, Y., He, T., Huang, D., Pardo, C. A., and Ransohoff, R. M. (2001). TNF- $\alpha$ mediates SDF- $1 \alpha$-induced NF- $\kappa \mathrm{B}$ activation and cytotoxic effects in primary astrocytes. J. Clin. Investig. 108, 425-435. doi: 10.1172/jci12629

\section{SUPPLEMENTARY MATERIAL}

The Supplementary Material for this article can be found online at: https://www.frontiersin.org/articles/10.3389/fphys. 2019.01182/full\#supplementary-material

FIGURE S1 | (A) HCAECs were incubated with cellROX and expression of ROS was measured via FACs. HCAECs pre-treated with SDF-1 $\alpha$ allogeneic conditioned media and autologous conditioned medium lowered ROS production stimulated by TBHP in 50, 33, and 30\%, respectively. (B) qPCR analysis of HCAECs stimulated with lipopolysaccharide (LPS) showed significantly upregulated NOS2 mRNA levels ( $9.85 \pm 1.62$ vs. PBS control $0.99 \pm 0.01, p=0.002)$, and only low dose (20 ng) of SDF-1 ( $\alpha$ downregulated NOS2 mRNA levels (4.07 \pm 0.03 vs. LPS $9.85 \pm 1.62, p=0.01)$.

Hare, J. M. (2010). "The dilated, restrictive and infiltrative cardiomyopathies," in Braunwald's Heart Disease: A Textbook of Cardiovascular Medicine, 9th Edn, eds R. O. Bonow, D. Mann, D. Zipes, and P. Libby (Philadephia, PA: Elsevier/Saunders).

Hare, J. M., DiFede, D. L., Rieger, A. C., Florea, V., Landin, A. M., El-Khorazaty, J., et al. (2017). Randomized comparison of allogeneic versus autologous mesenchymal stem cells for nonischemic dilated cardiomyopathy: POSEIDONDCM trial. J. Am. Coll. Cardiol. 69, 526-537. doi: 10.1016/j.jacc.2016.11.009

Hare, J. M., Fishman, J. E., Gerstenblith, G., DiFede Velazquez, D. L., Zambrano, J. P., Suncion, V. Y., et al. (2012). Comparison of allogeneic vs autologous bone marrow-derived mesenchymal stem cells delivered by transendocardial injection in patients with ischemic cardiomyopathy: the poseidon randomized trial. JAMA 308, 2369-2379.

Hare, J. M., Traverse, J. H., Henry, T. D., Dib, N., Strumpf, R. K., Schulman, S. P., et al. (2009). A randomized, double-blind, placebo-controlled, dose-escalation study of intravenous adult human mesenchymal stem cells (Prochymal) after acute myocardial infarction. J. Am. Coll. Cardiol. 54, 2277-2286. doi: 10.1016/j. jacc.2009.06.055

Hatzistergos Konstantinos, E., Saur, D., Seidler, B., Balkan, W., Breton, M., Valasaki, K., et al. (2016). Stimulatory effects of mesenchymal stem cells on cKit+ cardiac stem cells are mediated by SDF1/CXCR4 and SCF/cKit signaling pathways. Circ. Res. 119, 921-930. doi: 10.1161/CIRCRESAHA.116.309281

Hong, Y., Eleftheriou, D., Klein, N. J., and Brogan, P. A. (2015). Impaired function of endothelial progenitor cells in children with primary systemic vasculitis. Arthritis Res. Ther. 17, 292. doi: 10.1186/s13075-015-0810-3

Irani, K. (2000). Oxidant signaling in vascular cell growth, death, and survival. Circ. Res. 87, 179-183. doi: 10.1161/01.res.87.3.179

Iyer, S. S., and Rojas, M. (2008). Anti-inflammatory effects of mesenchymal stem cells: novel concept for future therapies. Expert Opin. Biol. Ther. 8, 569-581. doi: $10.1517 / 14712598.8 .5 .569$

Jarrah, A. A., Schwarskopf, M., Wang, E. R., LaRocca, T., Dhume, A., Zhang, S., et al. (2018). SDF-1 induces TNF-mediated apoptosis in cardiac myocytes. Apoptosis 23, 79-91. doi: 10.1007/s10495-017-1438-3

Kanelidis, A., Premer, C., Lopez, J. G., Balkan, W., and Hare, J. M. (2016). Route of delivery modulates the efficacy of mesenchymal Stem cell therapy for myocardial infarction: a meta-analysis of preclinical studies and clinical trials. Circ. Res. 120, 1139-1150. doi: 10.1161/CIRCRESAHA.116.309819

Karantalis, V., and Hare, J. M. (2015). Use of mesenchymal stem cells for therapy of cardiac disease. Circ. Res. 116, 1413-1430. doi: 10.1161/CIRCRESAHA.116. 303614

Karantalis, V., Suncion-Loescher, V. Y., Bagno, L., Golpanian, S., Wolf, A., Sanina, C., et al. (2015). Synergistic effects of combined cell therapy for chronic ischemic cardiomyopathy. J. Am. Coll. Cardiol. 66, 1990-1999. doi: 10.1016/j.jacc.2015. 08.879

Kijowski, J., Baj-Krzyworzeka, M., Majka, M., Reca, R., Marquez, L. A., Christofidou-Solomidou, M., et al. (2001). The SDF-1-CXCR4 axis stimulates VEGF secretion and activates integrins but does not affect proliferation and survival in lymphohematopoietic cells. Stem Cells 19, 453-466. doi: 10.1634/ stemcells.19-5-453 
Munzel, T., Sinning, C., Post, F., Warnholtz, A., and Schulz, E. (2008). Pathophysiology, diagnosis and prognostic implications of endothelial dysfunction. Ann. Med. 40, 180-196. doi: 10.1080/07853890701854702

Mushtaq, M., DiFede, D. L., Golpanian, S., Khan, A., Gomes, S., Mendizabal, A., et al. (2014). Rationale and design of the percutaneous stem cell injection delivery effects on neomyogenesis in dilated cardiomyopathy (the POSEIDONDCM study): a phase I/II, randomized pilot study of the comparative safety and efficacy of transendocardial injection of autologous mesenchymal stem cell versus allogeneic mesenchymal stem cells in patients with nonischemic dilated cardiomyopathy. J. Cardiovasc. Transl. Res. 7, 769-780. doi: 10.1007/s12265014-9594-0

Panth, N., Paudel, K. R., and Parajuli, K. (2016). Reactive oxygen species: a key hallmark of cardiovascular disease. Adv. Med. 2016:9152732.

Petit, I., Jin, D., and Rafii, S. (2007). The SDF-1-CXCR4 signaling pathway: a molecular hub modulating neo-angiogenesis. Trends immunol. 28, 299-307. doi: 10.1016/j.it.2007.05.007

Premer, C., Blum, A., Bellio, M. A., Schulman, I. H., Hurwitz, B. E., Parker, M., et al. (2015). Allogeneic mesenchymal stem cells restore endothelial function in heart failure by stimulating endothelial progenitor cells. EBioMedicine 2, 467-475. doi: 10.1016/j.ebiom.2015.03.020

Prockop, D. J., and Youn Oh, J. (2012). Mesenchymal stem/stromal cells (MSCs): role as guardians of inflammation. Mol. Ther. 20, 14-20. doi: 10.1038/mt. 2011.211

Ridker, P. M., Rifai, N., Pfeffer, M., Sacks, F., Lepage, S., and Braunwald, E. (2000). Elevation of tumor necrosis Factor- $\alpha$ and increased risk of recurrent coronary events after myocardial infarction. Circulation 101, 2149-2153. doi: 10.1161/ 01.cir.101.18.2149

Roura, S., and Bayes-Genis, A. (2009). Vascular dysfunction in idiopathic dilated cardiomyopathy. Nat. Rev. Cardiol. 6, 590-598. doi: 10.1038/nrcardio.2009.130

Seemann, S., and Lupp, A. (2016). Administration of AMD3100 in endotoxemia is associated with pro-inflammatory, pro-oxidative, and pro-apoptotic effects in vivo. J. Biomed. Sci. 23, 68-68

Shao, Y., Cheng, Z., Li, X., Chernaya, V., Wang, H., and Yang, X.-F. (2014). Immunosuppressive/anti-inflammatory cytokines directly and indirectly inhibit endothelial dysfunction- a novel mechanism for maintaining vascular function. J. Hematol. Oncol. 7:80. doi: 10.1186/s13045-0140080-6

Shibata, W., Ariyama, H., Westphalen, C. B., Worthley, D. L., Muthupalani, S., Asfaha, S., et al. (2013). Stromal cell-derived factor-1 overexpression induces gastric dysplasia through expansion of stromal myofibroblasts and epithelial progenitors. Gut 62, 192-200. doi: 10.1136/gutjnl-2011-301824

Tögel, F., Hu, Z., Weiss, K., Isaac, J., Lange, C., and Westenfelder, C. (2005). Administered mesenchymal stem cells protect against ischemic acute renal failure through differentiation-independent mechanisms. Am. J. Physiol. Ren. Physiol. 289, F31-F42.

Tompkins, B. A., DiFede, D. L., Khan, A., Landin, A. M., Schulman, I. H., Pujol, M. V., et al. (2017). Allogeneic mesenchymal stem cells ameliorate aging frailty: a phase II randomized, double-blind, placebo-controlled clinical trial. J. Gerontol. A Biol. Sci. Med. Sci. 72, 1513-1522. doi: 10.1093/gerona/glx137

Williams, A. R., and Hare, J. M. (2011). Mesenchymal stem cells: biology, pathophysiology, translational findings, and therapeutic implications for cardiac disease. Circ. Res. 109, 923-940. doi: 10.1161/CIRCRESAHA.111. 243147

Wojakowski, W., Kucia, M., Milewski, K., Machaliński, B., Hałasa, M., Buszman, P., et al. (2008). The role of CXCR4/SDF-1, CD117/SCF, and c-met/HGF chemokine signalling in the mobilization of progenitor cells and the parameters of the left ventricular function, remodelling, and myocardial perfusion following acute myocardial infarction. Eur. Heart J. Suppl. 10, K16-K23.

Zhang, H., Park, Y., Wu, J., Chen Xiu, P., Lee, S., Yang, J., et al. (2009). Role of TNF$\alpha$ in vascular dysfunction. Clin. Sci. 116, 219-230. doi: 10.1042/cs20080196

Zhang, Y., Dépond, M., He, L., Foudi, A., Kwarteng, E. O., Lauret, E., et al. (2016). CXCR4/CXCL12 axis counteracts hematopoietic stem cell exhaustion through selective protection against oxidative stress. Sci. Rep. 6:37827. doi: 10.1038/ srep 37827

Conflict of Interest Statement: $\mathrm{CP}$ and JH reported having a materials and methods patent for endothelial dysfunction. JH reported having a patent for cardiac cell-based therapy. He holds equity in Vestion Inc., and maintains a professional relationship with Vestion Inc., as a consultant and member of the Board of Directors and Scientific Advisory Board. JH is the Chief Scientific Officer, a compensated consultant and advisory board member for Longeveron, and holds equity in Longeveron. JH is also the co-inventor of intellectual property licensed to Longeveron. Longeveron, LLC and Vestion Inc., did not participate in funding this work.

The remaining authors declare that the research was conducted in the absence of any commercial or financial relationships that could be construed as a potential conflict of interest.

Copyright (c) 2019 Premer, Wanschel, Porras, Balkan, Legendre-Hyldig, Saltzman, Dong, Schulman and Hare. This is an open-access article distributed under the terms of the Creative Commons Attribution License (CC BY). The use, distribution or reproduction in other forums is permitted, provided the original author(s) and the copyright owner(s) are credited and that the original publication in this journal is cited, in accordance with accepted academic practice. No use, distribution or reproduction is permitted which does not comply with these terms. 